\title{
Scrutiny of the Structural Stability of CMSX-4 and NIMONIC 901 made Gas Turbine Fixed blades with Showerhead Cooling
}

\author{
Dr.R.Saravanan*, M.Karuppasamy \\ *Principal \& Professor, Department of Mechanical Engineering, Elenki Institute of Engineering and \\ Technology, Hyderabad, TS, India. Email: dr.rsaravanan@yahoo.com \\ Associate Professor\& Head of the, Department of Mechanical Engineering, S. Veerasamy Chettiar College of \\ Engineering and Technology, Puliangudi, TN, India.Email: prekar@yahoo.com
}

\begin{abstract}
Nowadays, the practice of increasing the inlet temperature of the thermal devices like the gas turbines is existed for improving their net shaft work and their thermal efficiency. The higher the operating temperature affects the structural stability of the components. The structural stability is usually influenced by its profile and other physical shape design, type of cooling design employed, operating temperature, physical chemical nag mechanical properties at elevated temperature and loading conditions. In this research the design and cooling type are predefined. The objective of the research to investigate the appropriateness of the suitability suggested material. The investigations on the materials under the dynamic loading conditions at elevated temperature were made to find the suitability. The Pro $-E$ used to model the blade and the ANSYS R14 work bench employed for conducting the analysis. The investigations were made separately for both materials. The results are discussed towards the appropriateness towards the guide vane designed and a minor correction in design was also suggested.
\end{abstract}

Index Terms - Showerhead cooling, structural stability, Gas turbine, guide vanes, Nimonic, CMSX.

\section{I.INTRODUCTION}

Gas turbine applications can be found high temperature applications like aircraft, marine propulsion, locomotive, power generation, and other industrial prime movers. In a thermal device like gas turbine the inlet temperature raised to improve the work output as well as efficiency. The rise of temperature usually 1000 to $1500^{\circ} \mathrm{C}$ [1-3]. In some specific cases like aerospace applications as much high as $1,727^{\circ} \mathrm{C}$ [4-6], the pressure ratio also high at compressor about 50 [6]. In Such situations the components often encounter the thermal damages as well as other damages like melting, corrosion, oxidation and erosion [7], the degradation of local or global structural strengths of blades, vanes and other components and it was estimated that half of the lifespan of the blades gets reduced due to small temperature difference by improper cooling $[3,6,9]$. The specific damages are: blade trailing-edge cracks [8], buckling and risk of blade failure [11], thermal-fatigue $[8,10,11]$. Hence the perfect cooling is insisted for avoiding them. Many studies were conducted on optimization of lip thickness to slot height ratio $(\mathrm{t} / \mathrm{H})$ in trailing edge cooling of blades and vanes [12 -17] in which Kacker et al. [12,13] considered lip thickness constant to estimate film cooling effectiveness, Taslim et al [14,15] varies slot geometries and blowing ratios. The $\mathrm{t} / \mathrm{H}$ ratio from 0.5 to 1 , decrease the overall film-cooling effectiveness by about $10 \%$ [1416]. The decreases of $\mathrm{t} / \mathrm{H}$ ratio, increases the film-cooling effectiveness [17-19]. [20] considered a a rectangular divergent channel which consists of serpentine shape with ribs, dimples/protrusions, guide vanes, and pin fins at the tip turning the region for his heat transfer studies. [21] studied the cooling performance at tip surfaces of guide vanes and blades at turning regions and insisted the importance of proper design to obtaining desired effects. [22] recommended installing guide vanes in the tip turning regions most suitable way to improve cooling of tip surfaces. [23] insisted that selection appropriate cooling technique with respect to configuration is must. The authors suggested two pass channels cooling at moving blades. This research work investigates with materials behaviors at elevated temperature for showerhead cooling design on gas turbine fixed blade (guide vane). The Pro-E and ANSYS are employed to design and analysis. ANSYS is generally the preferred tool for analyzing structural stability. [24] used CATIA and ANSYS to design and investigate the structural stability of various components of Two-Wheeled Inverted Pendulum. In later [25] investigated the suitability of Kevlar29/epoxy composite for drive shaft. The influence of cooling design such as impingement and shower head type on gas turbine guide vanes which are made up of Nimonic 901[26], RENE 77 [27], CMSX 4 [28] were reported. The sample guide vane of gas turbine is shown in Fig.1. This research investigates the structural stability of the identifies the material influences for the specific cooling design with the help of design softwares.

\section{MATERIALS AND METHODS}

The high temperature materials like CMSX-4 and NIMONIC 901 were considered in this investigation. The design approach is used for investigating the structural stability of gas turbine guide vanes at elevated temperature.

\section{A. $\quad$ CMSX 4}

It is a single crystal super alloy and gives more stability at elevated temperature. Its significant properties at high temperatures includes impact strength, rupture strength, fracture toughness. The blades which made up of 
CMSX-4, exhibited good performances as well as extended life span [29-32]. Hence its physical and mechanical properties were included in this analysis of structural stability of specified cooling designed guide vanes of gas turbine and reduced weight [30].

\section{B. NICKEL ALLOY 901/ NIMONIC 901}

It is also nickel based super alloy widely applicable at high temperature environments. Superior creep resistance, high yield strength, good forging characters, etc. at elevated temperature are the merits of this material. Its significant properties were included in the structural stability analysis by using ANSYS.

\section{STRUCTURAL ANALYSIS}

The modelling works were carried out Pro/E and analysis works were done at ANSYS 14.5 work bench. The dimensional particulars of the guide vane with showerhead cooling design is shown in Figure 2. The 3D meshed model is presented in Figure 3. The structural -

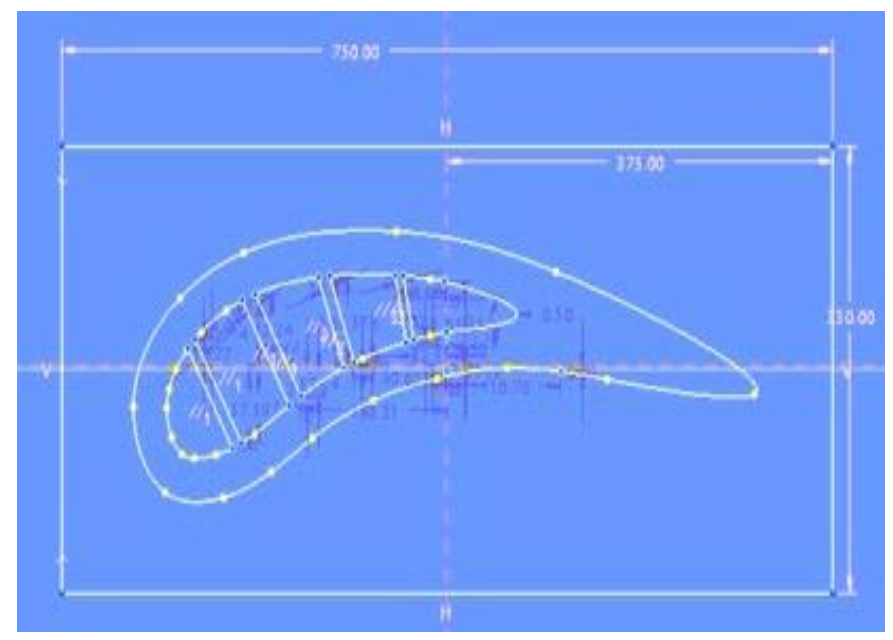

Figure 2 2D model of the Guide vane

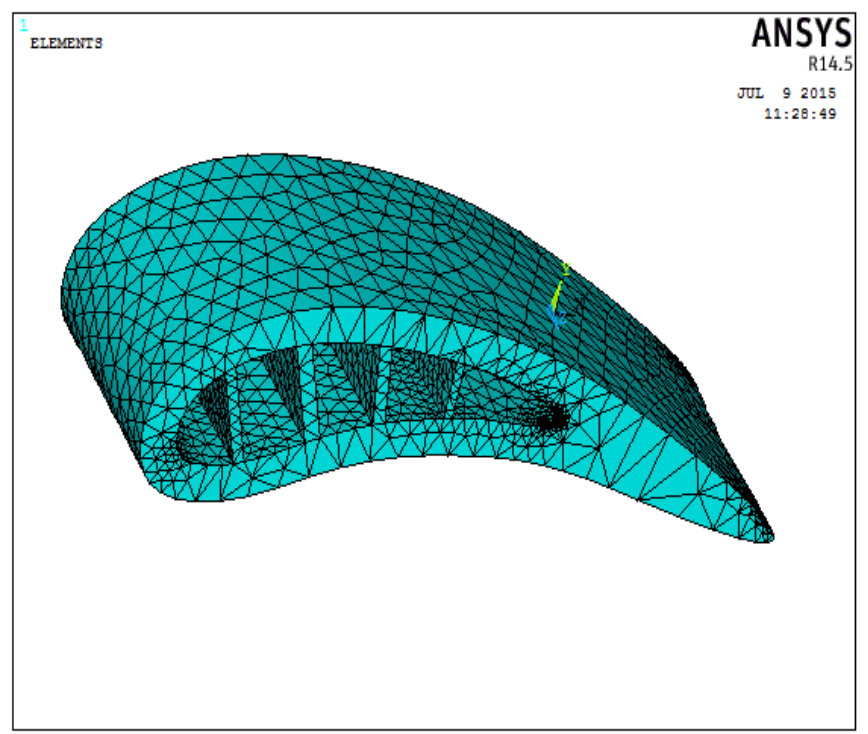

Figure 3 Meshed model of Guide vane - analysis like stress analysis, strain analysis and displacement analysis were considered. The comparative study of materials involved in manufacture them is focused on this research. The young's modulus 294000 Mpa, material density $0.00000774 \mathrm{~kg} / \mathrm{mm} 3$, Poisson Ratio 0.3 were considered for CMSX 4 made blades. In case of CMSX-4 made blades, the young's modulus 200000 $\mathrm{MPa}$, Poisson Ratio 0.30, material density 0.000077 $\mathrm{kg} / \mathrm{mm} 3$. In the meshed model made with 186 nodes, and pressure 0.188 N.mm2. The displacement analysis carried at ANSYS 14.5 work bench. The displacement with respect to turbine load was observed and shown them for CMSX 4 made blades in Figure 4 and for CMSX-4 made blades in Figure 5. The maximum displacements were observed on the concave side of cooling passage near by its sharp turning. The stress analysis for the above said blades (Figure 6 for CMSX 4 made blades and Figure 7 for CMSX-4 made blades

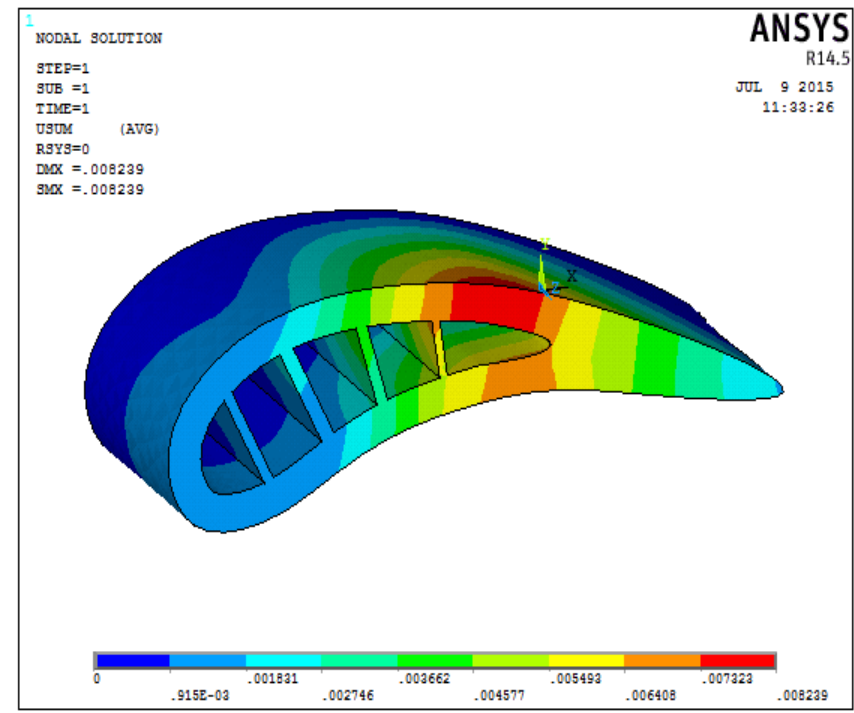

Figure 4. Displacement analysis on NIMONIC 901 blade

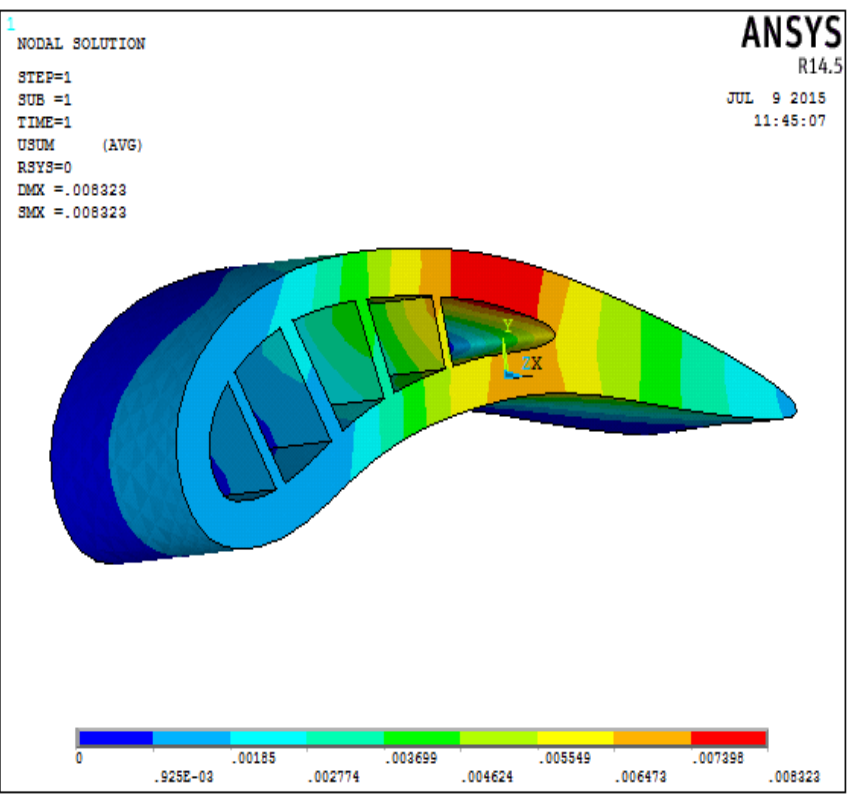

Figure 5. Displacement analysis on CMSX-4 blade 


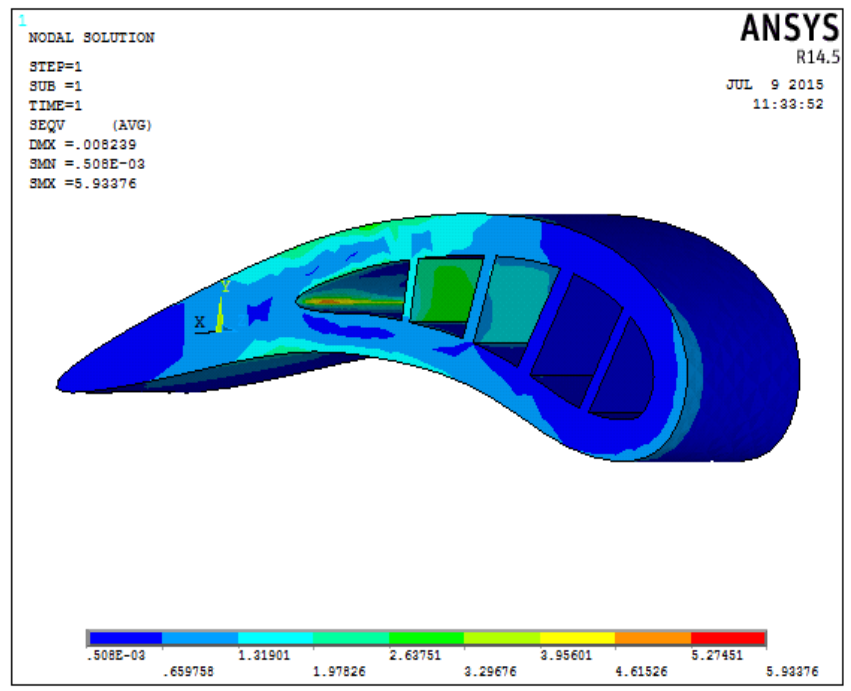

Figure 6. Stress analysis on NIMONIC 901 blade

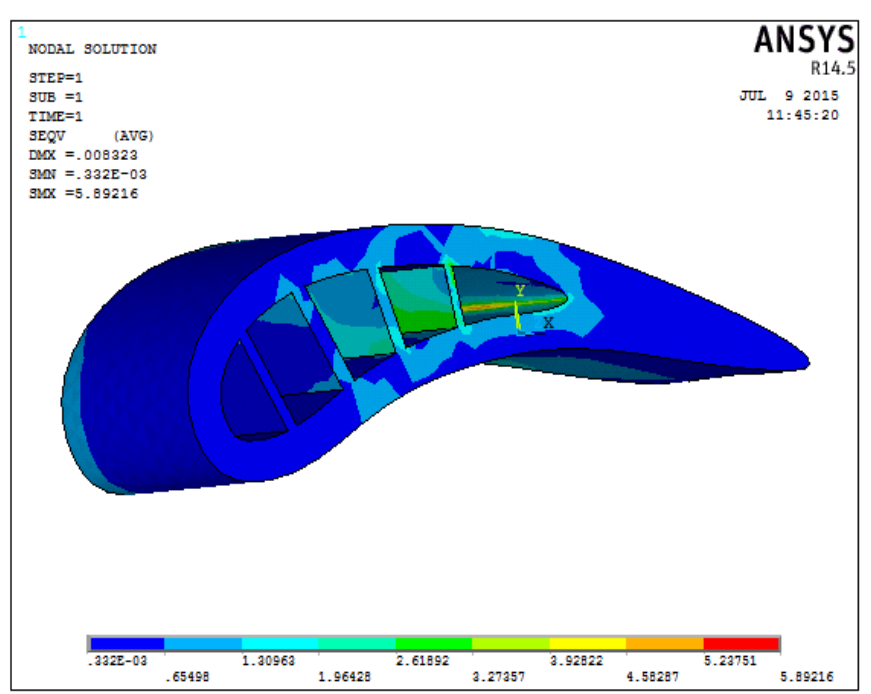

Figure 7. The stress analysis on CMSX-4 blade

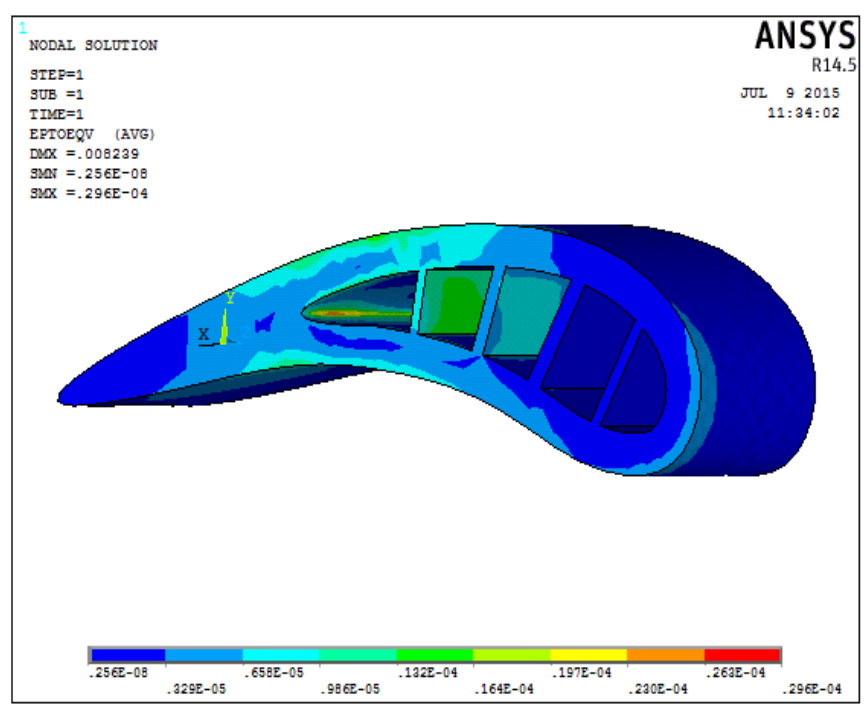

Figure 8. Strain analysis on NIMONIC 901 blade

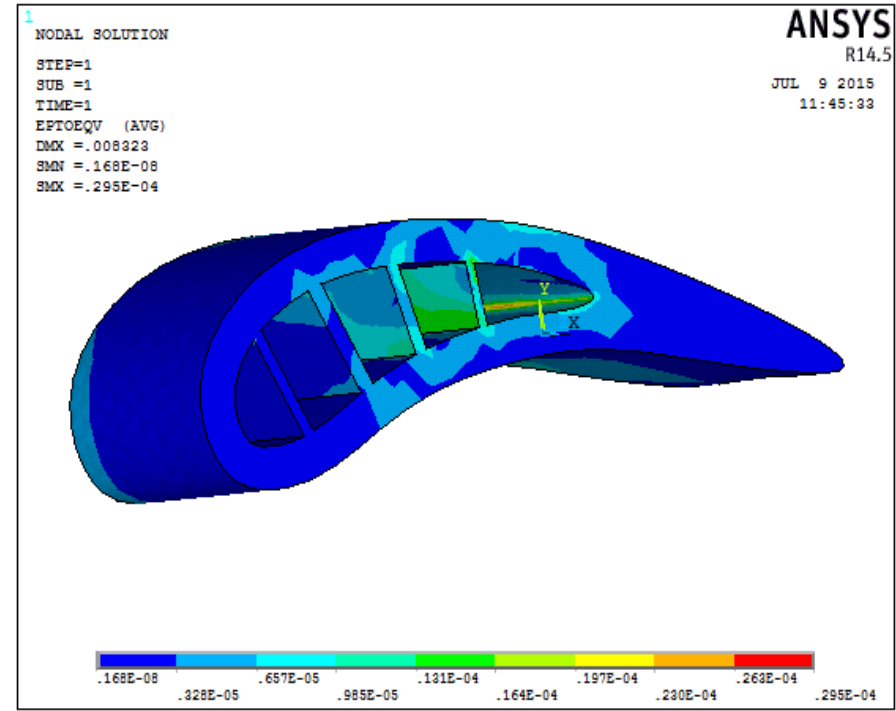

Figure 9. Strain analysis on CMSX-4 blade

Table 1 Results of Structural Analysis

\begin{tabular}{|c|c|c|c|}
\hline $\begin{array}{c}\text { Guide vane } \\
\text { Made up of }\end{array}$ & $\begin{array}{c}\text { Displacement } \\
(\mathbf{m m})\end{array}$ & $\begin{array}{c}\text { Stress } \\
(\mathbf{N} / \mathbf{m m} 2)\end{array}$ & Strain \\
\hline NIMONIC-901 & 0.11245 & 17.941 & $8.95 \mathrm{E}-05$ \\
\hline CMSX-4 & 0.77861 & 18.4091 & $6.30 \mathrm{E}-05$ \\
\hline
\end{tabular}

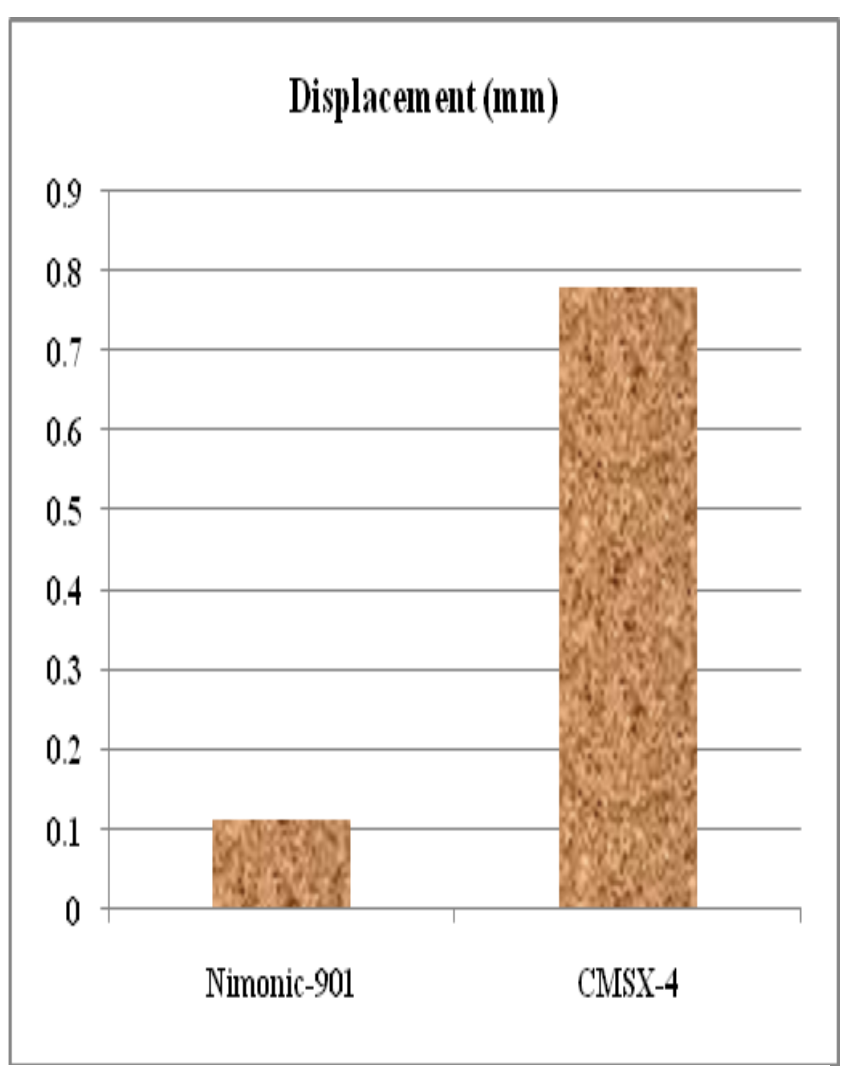

Figure 10 Results of Displacement Analysis 


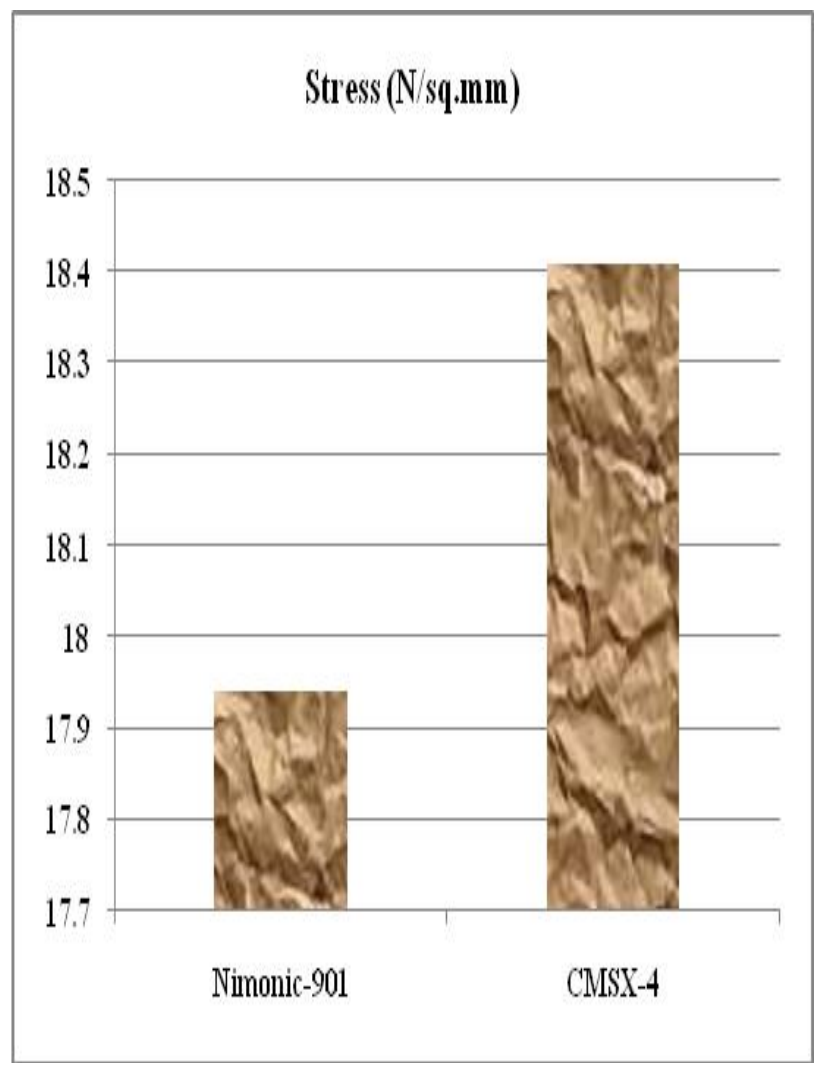

Figure 11 Results of Stress Analysis

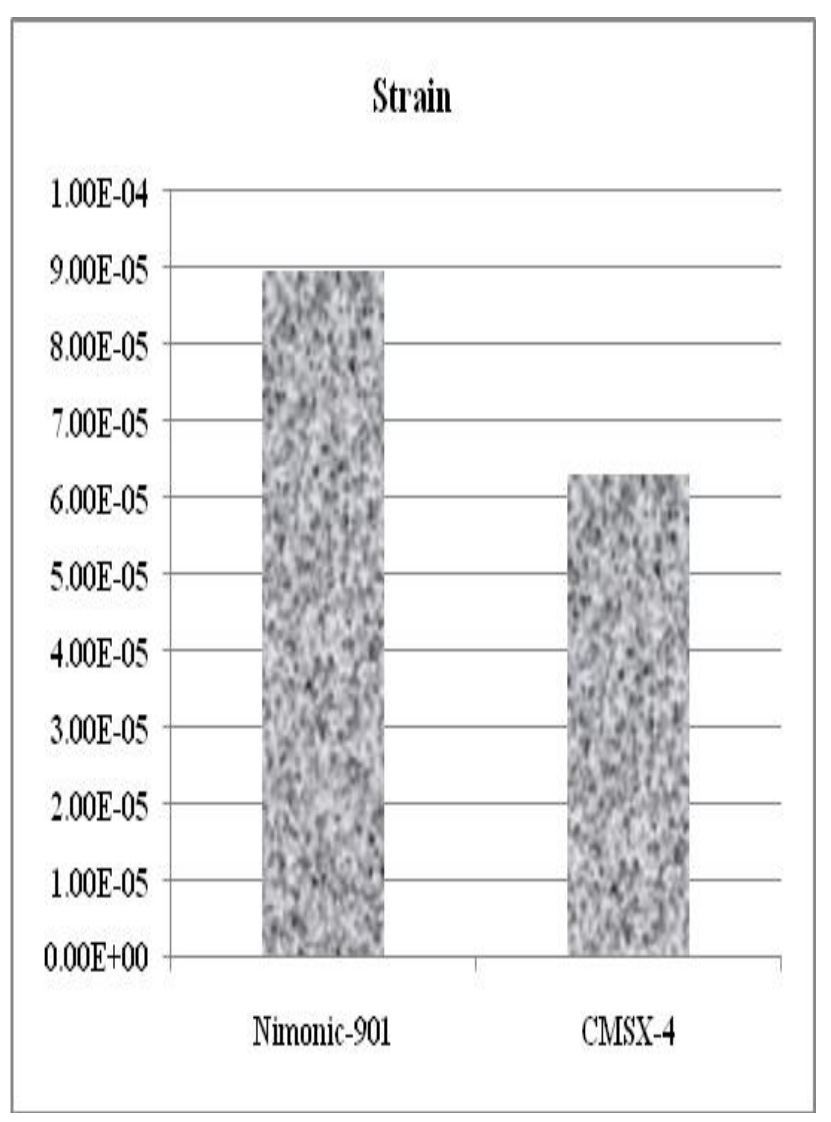

Figure 12 Results of Strain analysis

\section{RESULTS AND DISCUSSIONS}

The structural analysis on NIMONIC-901 and CMSX4 made guide vanes with showerhead type cooling design were carried out. The results are consolidated and presented in the Table1. The results are graphically evaluated and illustrated in Figure 10 shows the results of the displacement analysis. Figure 11 shows the results of stress analysis and the Figure 12 shows the results of the strain analysis. The overall result reveals that both the materials are performing well under in the tested condition for displacement as well as strain. The stress bearing capacity per square millimeter little higher for NIMONIC901 (Refer Figure 11). The higher values of stress, strain and displacements were noticed at a sharp turning of cooling design and its nearby. Such sharp turning corner may be encountered a cause of failure of blades

\section{CONCLUSION}

The cooling design and material which it is made up of are responsible for the structural stability of the gas turbine guide vanes at elevated temperature. The NIMONIC-901 and CMSX-4 made blades were considered for investigation with the showerhead type cooling design. The Investigated results exhibit both the blade are structurally stable at the elevated temperature. But the NIMONIC-901 made blade has little more stress bearing capacity than the CMSX-4 blade with equivalent flexibility. The high-stress formation, the more Displacement and more strain were encountered at the sharp turning of cooling design. Hence this investigation recommended that the sharp turning may be avoided in that cooling design.

\section{ACKNOWLEDGEMENT}

The authors acknowledge, the Chairman, Mr.E.Sadasiva Reddy, the Secretary, Mr.E.Dayakar Reddy, The Director Dr.M.Sambasiva Reddy and The Advisor, Dr.G.Ravender Reddy of Ellenki Group of Institutions for their continuous support and encouragement for our research.

\section{REFERENCES}

[1] J. C. Han and S. Ekkad, "Recent Studies in Turbine Blade Film Cooling”, J. Rotating Machinery, 7(1), 21-40, 2001.

[2] J. C. Han, "Recent Studies in Turbine Blade Cooling", J. Rotating Machinery, 10(6), 443-457, 2004.

[3] Facchini B, Innocenti L, Tarchi L. Pedestal and Endwall Contribution in Heat Transfer in Thin Wedge Shaped Trailing Edge. ASME. Turbo Expo: Power for Land, Sea, and Air, 3,101111, 2004.

[4] Martini P, Schulz A, Wittig S. Experimental and Numerical Investigation of Trailing Edge Film Cooling by Circular Coolant Wall Jets Ejected From a Slot With Internal Rib Arrays. ASME. Turbo Expo: Power for Land, Sea, and Air, Parts A and B, 5, 7179, 2003.

[5] P. Martini and A. Schulz, "Experimental and Numerical Investigation of Trailing Edge Film Cooling by Circular Wall Jets 
Ejected from a Slot with Internal Rib Arrays", J. Turbomachinery, 126(2), 229-236, 2004.

[6] Sunden B, Xie G. "Gas turbine blade tip heat transfer and cooling: a literature survey. Heat Transf Engineering, 31, 527-554, 2010.

[7] T. Horbach, A. Schulz and H. -J. Bauer, "Trailing Edge Film Cooling of Gas Turbine Airfoils - External Cooling Performance of Various Internal Pin Fin Configurations," J. Turbomachinery, 133(94), 041006-1 - 041006-9, 2011.

[8] Z. Yang and H. Hu, "An Experimental Investigation on the Trailing-edge Cooling of Turbine Blades," J. Propulsion and Power Research, 1(1), 36-47, 2012.

[9] Facchini B, Simonetti F, Tarchi L, "Experimental Investigation of Turning Flow Effects on Innovative Trailing Edge Cooling Configurations With Enlarged Pedestals and Square or Semicircular Ribs", ASME. Turbo Expo: Power for Land, Sea, and Air, Heat Transfer, Parts A and B: 795-806, 2009.

[10] J. Choi, S. Mhetras, J. -C. Han, S. Lau and R. Rudolph, "Film Cooling and Heat Transfer on Two Cutback Trailing Edge Model with Internal Performance Blockages”, J. Heat Transfer, vol.130, no.1, pp.012201-012213, 2008.

[11] L. Brundage, M. W. Plesniak, P. B. Lawless and S. Ramadhyani, "Experimental Investigation of Airfoil Trailing Edge Heat Transfer and Aerodynamic Losses", J. Experimental Thermal and Fluid Science, 31(3), 249-260, 2007.

[12] S. C. Kacker and J. Whitelaw, "The Effect of Slot Height and SlotTurbulence Intensity on the Effectiveness of the Uniform Density, Two Dimensional Wall Jet”. J. Heat Transfer, 90(4), 469-475, 1968.

[13] S. C. Kacker and J. H. Whitelaw, "An Experimental Investigation of Slot Lip Thickness on Impervious Wall Effectiveness of the Uniform Density, Two-Dimensional Wall Jet", J. Heat and Mass Transfer, 12(9), 1196-1201,1969.

[14] N. E. Taslim, S. D. Spring and B. P. Mehlmann, "An Experimental Investigation of Film Cooling Effectiveness for Slot Various Exit Geometries", Journal of Thermophysics and Heat Transfer, 6(2), 302-307, 1990.

[15] N. E. Taslim, S. D. Spring and B. P. Mehlmann, (1992), "Experimental Investigation of Film Cooling Effectiveness for Slot of Various Exit Geometries", J. Thermophysics and Heat Transfer, vol. 6 , no.2, pp.302-307.

[16] F. J. Cunha and M. K. Chyu, "Trailing-Edge Cooling for Gas Turbines", J. Propulsion and Power, 22(2), 286-300, 2006.

[17] R. J. Goldstein, "Film Cooling", J. Advance Heat Transfer, 7, 321$379,1971$.

[18] S. Sivasegaram and J. Whitelaw, "Film Cooling Slots: The Importance of Lip Thickness and Injection Angle", J. Mechanical Engineering Science, 11(1), 22-27, 1969.

[19] W. Burns and J. Stollery, "The Influence of Foreign Gas Injection and Slot Geometry on Film Cooling Effectiveness", J. Heat and Mass Transfer, 12(8), 935-951,1969.

[20] M.S.Lee, S.S.Jeong, S.W.Ahn, J.C.Ha, "Effects of angled ribs on turbulent heat transfer and friction factors in a rectangular divergent channel”, Int J Therm Sci., 84, 1-8, 2014.

[21] Xie Gongnan, Zhang Weihong, Sund en Bengt, "Computational analysis of the influences of guide ribs/vanes on enhanced heat transfer of a turbine blade tip-wall", Int J Therm Sci., 51, 184-194, 2012.

[22] Jiang Lei, S.J.L, J.C.Han, L.Zhang, H.K.Moon, "Effect of a turning vane on heat transfer in rotating multipass rectangular smooth channel", J Thermophys Heat Transf., 28(3), 417-427, 2014.

[23] Wang Chenglong, Wang Lei, Sunden Bengt, "Heat transfer and pressure drop in a smooth and ribbed turn region of a two-pass channel”, Appl Therm Eng., 85, 225-233, 2015.

[24] R. Saravanan, R. Pugazhenthi, P. Vivek and M. Santhanam, "Design and Simulation of a Two-Wheeled Inverted Pendulum - a Balanced, Easy Moving Vehicle for the Material Handling", American-Eurasian Journal of Scientific Research, 11(3), 189-198, 2016.

[25] R. Saravanan, P Vivek, T Vinod Kumar, "Is Kevlar29/Epoxy Composite an Alternate for Drive Shaft?", Journal of Advances in Mechanical Engineering and Science, 2(3), 1-13, 2016.
[26] Dr.R.Saravanan and G.Vinoth Reddy, "Structural Investigation on Nemonic-901 made Gas Turbine Guide Vanes" Global Journal of Engineering Science and Research Management, 4(4), 89-94, 2017.

[27] Dr.R.Saravanan and G.Vinoth Reddy "Structural Investigation on Cooling Design influences in Rene-77 made Gas Turbine Guide Vanes " International Journal of Advanced Scientific Technologies, Engineering and Management Sciences, 3(5), 7-11, 2017.

[28] Dr.R.Saravanan and G.Vinoth Reddy, "Investigation On Influence of Cooling Design In Structural Stability Of CMSX-4 Made Gas Turbine Guide Vanes" International Journal of Science and Research, 6(4), 2522-2526, 2017.

[29] J.Lapin, T.Pelachová, M.Gebura, "The effect of creep exposure on microstructure stability and tensile properties of single crystal nickel based superalloy CMSX-4" Kovove Materials, 50(6), 379386, 2012.

[30] A. Ma, D. Dye, R.C. Reed, "A model for the creep deformation 5ehavior of single-crystal superalloy CMSX-4", Acta Mater., 56(8), 1657-1670, 2008.

[31] J. Lapin, M. Gebura, T. Pelachová, M. Nazmy, "Coarsening kinetics of cuboidal gamma prime precipitates in single crystal nickel base super-alloy CMSX-4", Kovove Materials, 46(6), 313322, 2008 .

[32] Juraj Lapin, Tatiana Pelachová, Oto Bajana, "The Effect of Microstructure on Mechanical Properties of Single Crystal CMSX4 Superalloy, Proceedings of Metal 2013, Brno, Czech Republic, EU, 5, 15-17, 2013. 